\title{
Determinants of Common Mental Disorders Among People Living with HIV/AIDS Attending ART Service in Southern Ethiopia
}

\author{
Solomon Yimer $\mathbb{D}^{1}$ \\ Zeleke Girma $\mathbb{D}^{2}$ \\ Nebiyu Mengistu (D) \\ Seid Shumye (D) \\ 'Department of Psychiatry, Dilla \\ University, Dilla, Ethiopia; ${ }^{2}$ School of \\ Public Health, Dilla University, Dilla, \\ Ethiopia
}

Correspondence: Solomon Yimer Email sopsycha@gmail.com
Background: Worldwide, the rates of psychological problems have been shown to have a dramatic increase, particularly among people living with chronic diseases. Besides the known clinical factors, it is important to address an individual's level of resilience as an included factor for mental health outcome for people living with HIV/AIDS.

Aim: The aim of the study was to assess determinants of common mental disorders among people living with human immune virus/acquired immune deficiency virus (HIV/AIDS).

Setting: ART clinic of Gedeo zone public hospital, South, Ethiopia.

Methods: A facility-based unmatched case control study was conducted. A total of 360 adults (180 cases and 180 controls) aged 18 and above who attended the anti-retro viral therapy (ART) service participated. The Self-Reporting Questionnaire (SRQ-20) screening tool was used to determine cases and controls based on the status of common mental disorders. The treatment register at each HIV treatment center was used to systematically select study participants for the interview. The cases were common mental disorder (CMD) positively screened adults who scored seven and above, while the controls were adults who scored below seven. Then the cases and controls who took part in the study were selected using a simple random sampling method with a proportional allocation method for each hospital. Multivariable logistic regression was used. A p-value of less than 0.05 was considered statically significant.

Results: Lower resilience level was found to be significant predictors of common mental disorder among HIV patients $[\mathrm{AOR}=3.1695 \% \mathrm{CI} ; 1.83,5.46]$. The other predictors were being female (adjusted odds ratio $[\mathrm{AOR}]=2.0195 \% \mathrm{CI} ; 1.21,3.34$ ); single $[\mathrm{AOR}=8.10$ 95\% CI; 3.50, 18.76]; divorced and widowed [AOR = 3.31 95\% CI; 1.76, 6.22]; more than ten years of illness duration [AOR $=2.3095 \% \mathrm{CI}$; 1.39, 3.80]; and having perceived stigma [AOR $=5.39$ 95\% CI; 2.65, 10.82].

Conclusion: HIV-positive adults with lower resilience levels and experiencing perceived stigma exhibited significantly higher risk of mental disorders. Hence, improving personal resilience and working to mitigate perceived stigma play a great role in decreasing the risk of common mental disorders.

Keywords: resilience, HIV, acquired immune deficiency syndrome, depression, stigma

\section{Background}

According to a recent report, approximately 36.7 million people are infected with HIV, of which 34.5 million are adults and 1.8 million are newly infected, and they contribute to one million deaths from AIDS-related illnesses. ${ }^{1}$ Similarly, nearly 19.4 million people in Eastern and Southern African countries are living with HIV/ AIDS (accounting for 43\% of global new HIV infections and 420,000 AIDS-related 
deaths). ${ }^{2}$ Having a chronic illness subsequently affects an individual's mental health, leading to emotional disorders such as anxiety and depression. ${ }^{3}$

In the treatment and management of the HIV virus, adherence to antiretroviral therapy (ART) is critical. Because Anti Retro Viral (ARV) drugs should be used till the end of life, their continuing use and complications contribute to depression and other emotional disorders in those living with HIV/AIDS. However, in Sub-Saharan Africa, the average rate of adherence to ART is $72.9 \%{ }^{4,5}$

Despite having the goal of a 90-90-90 strategy (ninety percent diagnosis, ninety percent treatment, and ninety percent viral suppression), study reports in Ethiopia indicated that ART adherence remained below $90 \%$, particularly in the South. ${ }^{5}$

On the other hand, the absence of efficient ARV compliance led to disease progression due to increased viral load, which leads to emotional disorders such as depression. As a result, prevalent mental problems relate to disease severity, reduced quality of life, and contribute to unemployment and lower production. But from the other perspective, the escalating prevalence of mental problems among people living with HIV (PLWHIV) raises the likelihood of decreased health outcomes and productivity. ${ }^{6-8}$

At this instant, unlike other individuals, People Living with HIV/AIDS (PLWHA) are in great emotional need and require enormous support to overcome the burden of their illness. Similarly, contracting HIV/AIDS alone can lead an individual to difficulties related to self-esteem, coping mechanisms, social isolation, and finally to psychological disorders. ${ }^{9}$

The emotional burden of HIV/AIDS infection among PLWHIV is very heavy, compared to other populations. Various studies, for example, show that PLWHA has twice the rate of psychological problems, most notably depression, as the general population. ${ }^{9}$

Globally, around 450 million people suffer from illnesses related to mental or behavioral disorders. It was responsible for nearly one million suicide deaths. Approximately 4 to 6 years of living with a disability (YLD) are mainly due to depression, alcohol use, schizophrenia, and bipolar disorder. ${ }^{10}$ According to published research, between 44 and $58 \%$ of HIV positive people have mental disorders. ${ }^{11}$ In Sub-Saharan Africa, 10 to $20 \%$ of people living with HIV have major depression, and another 20 to $30 \%$ have elevated depressive symptoms or minor depression. ${ }^{12}$
Furthermore, studies show that continuing adversity, socioeconomic status, social support, family environment, coping skills, optimism and hope, and other factors are associated with either decreased or increased resilience or mental health outcomes, especially in adults with chronic medical conditions like HIV/AIDS. ${ }^{3,13}$

Resilience (ie, the ability to become strong, healthy, or successful again after major life hardship or stress) $)^{14}$ is an important predictor of mental disorder vulnerability among people who are living with HIV/AIDS. But on the other hand, a person's ability to recover from stress and serious mental health problems contributes to successful adherence and treatment outcome. ${ }^{15}$

Several systematic reviews have found a negative relationship between resilience and common mental disorders such as anxiety, depression, anxiety, and somatization. . $^{3,-20}$ Similarly, a cross-sectional study performed in the United Kingdom revealed that a longer time being diagnosed with HIV was related to lower resilience. In adults with HIV, high resilience is related to a lower prevalence of depression and anxiety. $^{21}$

Another cross-sectional study conducted in South Africa among HIV-infected women reported that higher levels of resilience were associated with lower levels of self-reported depression. ${ }^{22}$

Effective treatment of depression and other mental illnesses in people living with HIV/AIDS contributes to positive motivation and self-efficacy. As a consequence, research into critical factors influencing psychosocial health among individuals with HIV/AIDS will be used as input for the production and utilization of appropriate screening instruments and treatment options to treat mental health problems. ${ }^{23}$

People living with HIV/AIDS in Ethiopia are attending ART services, but mental health and resilience are not considered as an included factor in studies conducted previously, especially in the current study setting. The current study aimed to assess the determinants of common mental disorders among those who are receiving ART services.

\section{Methods}

\section{Study Design and Setting}

A facility-based unmatched case control study was conducted among people living with HIV/AIDS and who attended the ART service in the Gedeo Zone public hospital, South Ethiopia. The capital city of the zone is Dilla Town. The town is $370 \mathrm{~km}$ away from Addis Ababa (the 
capital of Ethiopia). The Gedeo zone has six provinces and two city administrations with a total population of $1,086,768$. Of them, $49 \%$ were males, and $51 \%$ were females, with an area of 1210.89 square kilometers. The zone had one referral hospital, three district hospitals, and 38 health centers. The zone had one referral hospital, three district hospitals, and 38 health centers. The study was conducted from May to June 2019. G.C.

\section{Population}

In this study, the cases were common mental disorder positive adults, while the controls were common mental disorder negative. Both attended ART services located in one of the Gedeo zone public hospitals during the study period. Adults who were critically ill and unable to communicate were excluded from the study.

\section{Sample Size Determination and Sampling Procedure}

The sample size was computed based on a comparison of proportions between the case and the control using the following assumptions: Considering 95\% CI, 80\% power, case: control ratio of $1: 1$, and taking the proportion of exposure among cases to be $38 \%$ and among controls $24 \%$. Based on these, a maximum sample size of 171 cases and 171 controls. Adding a 10\% nonresponse rate, the final sample size for the study was calculated to be 188 cases and 188 controls.

Concerning the sampling procedure, primarily, the selection of the participants was started with obtaining the sampling frame at the specific public hospital HIV treatment center. Then, we visited the centers and we interviewed them using the Self-Reporting Questionnaire (SRQ-20) tool. We used the treatment register to systematically select study participants for the interview. Then, using a simple random sampling method, 188 CMD positive screened adults (cases) and 188 CMD negative screened (controls) were selected from each hospital based upon the proportional allocation method.

\section{Data Collection Instruments, Personnel and Quality Assurance}

The questionnaire consisted of socio-demographic characteristics, HIV/AIDS-related clinical factors, current substance use, resilience, and social support status. The questionnaire was modified after a pretest was conducted. Local language translated version of the questionnaire used to collect the data. The data was collected by four diploma nurses. Three supervisors were assigned to control the data collection process. A face-to-face interview was used to collect the data. Two days training was delivered on the data collection procedure and data collection tools for data collectors and supervisors.

\section{Measurements}

The Self-Reporting Questionnaire 20-item version (SRQ20) was used to assess common mental disorders. The tool was developed by the World Health Organization (WHO) to screen common mental disorders and has been validated in sub-Saharan countries. The optimal cutoff point for defining cases for CMD has also varied widely, from $\geq 4$ in Sudan to $\geq 10$ in South Africa. The tool has been validated in Ethiopia and translated into the Amharic version. A score of $>(=) 7$ indicated the presence of a common mental disorder. ${ }^{24}$

The Connor-Davidson Resilience Scale-10 item (CDRISC) was used to assess the level of resilience. Respondents rate 10 items on a scale ranging from 0 (not true at all) to 4 (true nearly all the time) and total scores range from 0 to 40, with higher scores reflecting greater resilience. The CD-RISC-10 has demonstrated good internal consistency. The Cronbach's alpha reliability coefficient was $0.91 .^{25}$

Perceived stigma was assessed using a 12 item HIV/ AIDS-related stigma scale. Internal consistency was demonstrated by the tool (Cronbach's alpha of 0.82-0.91). It is a 4-point Likert response where " 0 " represents the least (strongly disagree) and " 3 " represents the most (strongly agree) stigma. Participants who scored above the mean were considered stigmatized. ${ }^{26}$

In the current study, social support was measured using the Oslo 3 item social support scale (OSS-3), with a score of "3-8" indicated poor social support, a score of "9-11" indicated intermediate social support, and a score of " $12-$ 14 " indicated strong social support". 27

\section{Data Analysis}

EpiData version 3.1 was used for Data entry, cleaning; and analyzed by Statistical Package for Social Science (SPSS) version 20 software. Descriptive statistics were computed. The proportions of predictor variables were compared between the cases and the controls using the chi-square test. Crude association between common mental disorders and each independent variable was conducted using bivariate logistic regression analysis. Multivariable logistic 
regression was used to determine the adjusted odds ratio (AOR). 95\% confidence intervals were computed and a p-value $\leq$ of 0.05 was considered statistically significant. In this regard, the Hosmer and Lemeshow goodness-of-fit test was done to check the model's fit.

\section{Ethical Considerations}

Ethical clearance was obtained from the Institutional Review Board (IRB) of the College of Medicine and Health Science, Dilla University. Information was collected after obtaining informed consent from each participant. Confidentiality was maintained by an anonymous questionnaire. The study was conducted in accordance with the Declaration of Helsinki.

\section{Results}

A total of 360 people living with HIV/AIDS were interviewed, giving a response rate of $95.74 \%$. Of the total participants, 180 cases and 180, taking part in the study. The mean $\pm(\mathrm{SD})$ age of cases and controls was $35.4 \pm 8.7$ and $36.6 \pm 7.9$ years, respectively. Females constituted 117 $(65 \%)$ of cases and $91(50.56 \%)$ of controls. The frequency of non-employment is higher among controls compared to cases $(67.22 \%$ versus $57.78 \%)$. The proportion of participants aged $>(=) 39$ was found to be almost similar in both cases and controls (25.56\% versus $24.44 \%)$ (Table 1).

\section{Clinical Characteristics of People Living with HIVIAIDS}

One hundred twenty-four cases (68.89\%) are in the WHO stage first, and $61.11 \%$ of cases have been sick with HIV/ AIDS for more than ten years. On the other hand, the presence of Opportunistic Infections (OPIs) among cases and controls was almost similar (Table 2).

\section{Life Style Characteristics and Other Factors}

The proportion of current alcohol use was $38.89 \%$ among controls, while it was $42.22 \%$ among cases. On the other hand, the level of resilience was reported to be high among controls compared to cases (82.78\% vs 55.56\%) (Table 3). About $43.6 \%$ of the study participants had poor social support status and the proportion was different between cases and controls (Table 3).

\section{Determinants of Common Mental Disorders Among People with HIVIAIDS}

During the bivariate analysis current use of tobacco, sex, marital status, educational level of the participants, duration of illness after diagnosis, CD4 count, employment, perceived stigma, social support, and resilience level were found to be independent predictors of Common Mental Disorder (CMD) (Table 4).

Variables in the bivariate analysis $(\mathrm{P}<0.2)$ were carried over to the multivariable analysis. After adjusting for potential confounding factors, female sex, being single, divorced or widowed marital status, having $>(=) 10$ years of illness duration, having perceived stigma, and a lower resilience level were found to be significant predictors of CMD.

Females were found to be two times more likely to develop Common mental disorder (CMD) than males $(\mathrm{AOR}=2.0195 \% \mathrm{CI} ; 1.21,3.34)$. Similarly, widowed and divorced; and single marital status, were found to be three times and eight times more likely to have CMD than married ones $(\mathrm{AOR}=8.1095 \% \mathrm{CI} ; 3.50,18.76)$; $\mathrm{AOR}=$ $3.3195 \% \mathrm{CI} ; 1.76,6.22)$. The presence of perceived stigma was also identified as a risk factor, with the risk of developing CMD being 5.39 times higher than those with no stigma $(\mathrm{AOR}=5.3995 \% \mathrm{CI} ; 2.65,10.82)$. In addition, the duration of illness of ten and more than ten years was an independent risk factor for the development of $\mathrm{CMD}(\mathrm{AOR}=2.30$ 95\% CI; 1.39, 3.80). Furthermore, having a lower resilience level was a strong predictor with the risk of 3.16 times higher than higher resilience level (AOR=3.16 95\% CI; 1.83, 5.46) (Table 4).

\section{Discussion}

Apart from the usual predictors of common mental disorders, the level of resilience was identified to significantly affect common mental disorders among people with HIV/AIDS in the current study. Individuals with lower resilience levels were three times more likely to have a common mental disorders than those with higher resilience levels. The possible reason might be that a person's level of resilience to demanding life challenges and adversity determines the regularity of their interpersonal, social, cognitive, and behavioral health. Therefore, successful adaptation and swift recovery after experiencing life adversities like lifelong chronic illness determine the mental health status of the individual. ${ }^{28}$ However, other studies in Ethiopia did not study resilience levels 
Table I Socio-Demographic Characteristics of People with HIVI AIDS Attending ART Service in Gedeo Zone Public Hospitals, $2019(N=360)$

\begin{tabular}{|c|c|c|c|c|}
\hline \multirow[t]{2}{*}{ Variable } & \multicolumn{2}{|c|}{ Controls $(n=180)$} & \multicolumn{2}{|c|}{ Cases $(n=180)$} \\
\hline & $\mathbf{N}$ & $\%$ & $\mathbf{N}$ & $\%$ \\
\hline \multicolumn{5}{|l|}{ Sex } \\
\hline Male & 89 & 49.44 & 63 & 35 \\
\hline Female & 91 & 50.56 & 117 & 65 \\
\hline \multicolumn{5}{|l|}{ Age group } \\
\hline $18-28$ & 45 & 25 & 48 & 26.66 \\
\hline $29-38$ & 91 & 50.56 & 86 & 47.78 \\
\hline$\geq 39$ & 44 & 24.44 & 46 & 25.56 \\
\hline \multicolumn{5}{|l|}{ Marital status } \\
\hline Single & 24 & 13.33 & 47 & 26.11 \\
\hline Married & 144 & 80 & 90 & 50 \\
\hline Others* & 12 & 6.67 & 43 & 23.89 \\
\hline \multicolumn{5}{|l|}{ Religion } \\
\hline Protestant & 78 & 43.34 & 75 & 41.67 \\
\hline Orthodox & 67 & 37.22 & 70 & 38.89 \\
\hline Muslim & 22 & 12.22 & 17 & 9.44 \\
\hline Catholic & 13 & 7.22 & 18 & 10 \\
\hline \multicolumn{5}{|l|}{ Ethnicity } \\
\hline Gedeo & 56 & 31.11 & 74 & 41.11 \\
\hline Oromo & 51 & 28.33 & 33 & 18.33 \\
\hline Amhara & 30 & 16.67 & 36 & 20 \\
\hline Gurage & 20 & 11.11 & 26 & 14.44 \\
\hline Other & 23 & 12.78 & 11 & 6.11 \\
\hline \multicolumn{5}{|l|}{ Educational Status } \\
\hline Unable to read/write & 38 & 21.11 & 46 & 25.56 \\
\hline Primary & 77 & 42.78 & 71 & 39.44 \\
\hline Secondary & 48 & 26.67 & 38 & 21.11 \\
\hline$>1=$ Certificate & 17 & 9.44 & 25 & 13.89 \\
\hline \multicolumn{5}{|l|}{ Occupation } \\
\hline Employed & 59 & 32.78 & 76 & 42.22 \\
\hline Non-employed & 121 & 67.22 & 104 & 57.78 \\
\hline \multicolumn{5}{|l|}{ Living status } \\
\hline Both parents & 75 & 41.67 & 75 & 41.67 \\
\hline Single parent & 60 & 33.33 & 60 & 33.33 \\
\hline Other & 45 & 25 & 45 & 25 \\
\hline \multicolumn{5}{|l|}{ Residence } \\
\hline Rural & 40 & 28.6 & 38 & 21.11 \\
\hline Urban & 140 & 77.77 & 142 & 78.89 \\
\hline
\end{tabular}

Note: Others*: divorced and widowed.

and their association with a common mental disorder. Because of that, no evidence was reported on this aspect. However, the current study findings are similar to the
Table 2 Clinical Characteristics of People Living with HIV/AIDS Attending ART Service in Gedeo Zone Public Hospital, 2019 (N= 360)

\begin{tabular}{|l|l|l|l|l|}
\hline Variable & $\begin{array}{l}\text { Controls } \\
\mathbf{N}=180\end{array}$ & $\%$ & $\begin{array}{l}\text { Cases } \\
\mathbf{N}=180\end{array}$ & $\%$ \\
\hline $\begin{array}{l}\text { WHO clinical stage } \\
\text { First } \\
\text { Second }\end{array}$ & 132 & 73.33 & 124 & 68.89 \\
Third & 36 & 20 & 38 & 21.11 \\
\hline $\begin{array}{l}\text { Duration of HIVIAIDS } \\
\text { diagnosis } \\
<10 \text { yrs. }\end{array}$ & 12 & 6.67 & 18 & 10 \\
\hline$\geq 10$ yrs & 95 & 52.78 & 70 & 38.89 \\
\hline $\begin{array}{l}\text { CD4 count } \\
</=200 \text { CD4 }\end{array}$ & 85 & 47.22 & 110 & 61.11 \\
\hline 200 CD4 & 125 & 69.44 & 139 & 77.22 \\
\hline $\begin{array}{l}\text { ART type } \\
\text { First line } \\
\text { Second line }\end{array}$ & 55 & 30.56 & 41 & 22.78 \\
\hline $\begin{array}{l}\text { Opportunistic infections } \\
\text { No } \\
\text { Yes }\end{array}$ & 146 & 81.11 & 140 & 77.78 \\
\hline
\end{tabular}

Table 3 Life Style and Other Characteristics of People with HIV/ AIDS Attending ART Service in Gedeo Zone Public Hospitals, $2019(n=360)$

\begin{tabular}{|l|l|l|l|l|}
\hline Variable & Control $(\mathbf{n}=\mathbf{1 8 0})$ & $\%$ & Case (n=180) & $\%$ \\
\hline $\begin{array}{l}\text { Alcohol current } \\
\text { No }\end{array}$ & 110 & 61.11 & 104 & \\
Yes & 70 & 38.89 & 76 & 57.78 \\
\hline $\begin{array}{l}\text { Tobacco current } \\
\text { No }\end{array}$ & 128 & 71.11 & 115 & 42.22 \\
Yes & 52 & 28.89 & 65 & \\
\hline Khat current & & & & 36.89 \\
No & 85 & 47.22 & 75 & \\
Yes & 95 & 52.78 & 105 & 41.67 \\
\hline Resilience level & & & & 58.33 \\
Low & 31 & 17.22 & 80 & \\
High & 149 & 82.78 & 100 & 44.44 \\
\hline Perceived stigma & & & & 55.56 \\
No & 54 & 30 & 17 & \\
Yes & 126 & 70 & 163 & 9.44 \\
\hline Social support & & 33.89 & 96 & 53.56 \\
Poor & 61 & 48.33 & 55 & 30.56 \\
Moderate & 87 & 32 & 29 & 16.11 \\
Strong & & & & \\
\hline
\end{tabular}


Table 4 Determinants of Common Mental Disorder Among People Living with HIV/AIDS Attending ART Service in Gedeo Zone Public Hospitals, Ethiopia $(\mathrm{N}=360)$

\begin{tabular}{|c|c|c|c|c|c|}
\hline \multirow[t]{2}{*}{ Variable } & \multirow{2}{*}{$\begin{array}{l}\text { Control } \\
180\end{array}$} & \multirow{2}{*}{$\begin{array}{l}\text { Case } \\
180\end{array}$} & \multirow[t]{2}{*}{ COR(95\% Cl) } & \multirow[t]{2}{*}{ AOR(95\% Cl) } & \multirow[t]{2}{*}{ P-value } \\
\hline & & & & & \\
\hline \multicolumn{6}{|l|}{ Sex } \\
\hline Male & 89 & 63 & I & 1 & \\
\hline Female & 91 & 117 & $1.816(1.19,2.77)$ & $2.01(1.21,3.34)^{*}$ & 0.007 \\
\hline \multicolumn{6}{|l|}{ Marital status } \\
\hline Single & 24 & 47 & $3.133(1.79,5.47)$ & $3.3 \mathrm{I}(1.76,6.22)^{*}$ & 0.000 \\
\hline Divorced and widowed & 12 & 43 & $5.733(2.87,1.45)$ & $8.10(3.50,18.76)^{*}$ & 0.000 \\
\hline Married & 144 & 90 & 1 & 1 & \\
\hline \multicolumn{6}{|l|}{ Educational Status } \\
\hline Unable to read/write & 38 & 46 & $0.823(0.39,1.74)$ & $0.45(0.18,1.16)$ & 0.099 \\
\hline Primary & 77 & 71 & $0.627(0.31,1.26)$ & $0.45(0.19,1.03)$ & 0.060 \\
\hline Secondary & 48 & 38 & $0.538(0.26, I .14)$ & $0.40(0.16,0.99)$ & 0.048 \\
\hline$>/=$ Certificate & 17 & 25 & 1 & 1 & \\
\hline \multicolumn{6}{|l|}{ Occupation } \\
\hline Employed & 59 & 76 & 1 & 1 & \\
\hline Non-employed & $|2|$ & 104 & $1.499(0.98,2.32)$ & $1.31(0.78,2.19)$ & 0.300 \\
\hline \multicolumn{6}{|l|}{ CD4 count } \\
\hline$</=200$ & 125 & 139 & $1.492(0.93,2.39)$ & $1.09(0.61,1.97)$ & \\
\hline$>200$ & 55 & 41 & 1 & 1 & \\
\hline \multicolumn{6}{|l|}{ Resilience level } \\
\hline Low & 31 & 80 & $3.85(2.36,6.25)$ & $3.16(1.83,5.46)^{*}$ & 0.000 \\
\hline High & 149 & 100 & 1 & 1 & \\
\hline \multicolumn{6}{|l|}{ Duration of illness } \\
\hline$<10 \mathrm{yrs}$ & 95 & 70 & I & I & \\
\hline$\geq 10 \mathrm{yrs}$ & 85 & 110 & $0.01(1.76,1.15)$ & $2.30(1.39,3.80)^{*}$ & 0.001 \\
\hline \multicolumn{6}{|l|}{ Perceived stigma } \\
\hline No & 54 & 17 & 1 & 1 & \\
\hline Yes & 126 & 163 & 4.II $(2.27,7.43)$ & $5.39(2.65,10.82)^{*}$ & 0.000 \\
\hline \multicolumn{6}{|l|}{ Current tobacco use } \\
\hline No & 128 & 115 & 1 & 1 & \\
\hline Yes & 52 & 65 & $1.39(0.89,2.16)$ & $1.49(0.87,2.55)$ & 0.143 \\
\hline \multicolumn{6}{|l|}{ Social Support } \\
\hline Poor & 61 & 96 & I.74 $(0.96,3.15)$ & I.36 $(0.68,2.72)$ & 0.376 \\
\hline Moderate & 87 & 55 & $0.70(0.38,1.28)$ & $0.57(0.28,1.15)$ & 0.116 \\
\hline Strong & 32 & 29 & 1 & I & \\
\hline
\end{tabular}

Notes: ${ }^{*} \mathrm{P}<0.05$. I: reference category.

Abbreviations: COR, cumulative odds ratio; AOR, adjusted odds ratio.

study findings in countries other than Ethiopia. ${ }^{29,30}$ Similarly, evidences showed that engaging in a routine moderate physical exercise reduces the burden of depression and other neurological problems among people with HIV/AIDS. ${ }^{31-33}$

From the socio-demographic factors, female adults living with HIV/AIDs have significantly developed common mental disorders than male participants of the study. Accordingly, female individuals living with HIV/AIDs were about twice compared to males. This finding is also in line with a cross-sectional study conducted in Hawassa city, Ethiopia, ${ }^{34}$ and a metacognitive perspective. ${ }^{35}$ The possible reason for the difference might be that women are more likely to be exposed to conscious or unconscious 
neglect by society because of the effect of an illness. Moreover, susceptibility to large life burdens among women impacts their psychological and mental health.

Similarly, the prevalence of depressive and anxiety disorders has shown that women are twice as likely as men to suffer from the condition. ${ }^{36}$ This finding is in line with other findings. ${ }^{37,38}$

Single participants and participants having the marital status of being widowed and divorced were three times and eight times more likely to be at risk of a common mental disorder than married ones. This is because single or widowed people living with HIV/AIDs experience increased levels of chronic stress, mainly due to economic hardship and reduced levels of social support. This condition ultimately results in a deplorable standard of living in society. As a result, their marital status imposes a dual burden on their lives, in addition to a lifelong illness. ${ }^{39}$ The current finding is similar to the study results of other setups in Ethiopia and other countries. ${ }^{34,40,41}$

Perceived stigma and duration of illness among HIV patients were found to be correlated with the risk of developing a common mental disorder. HIV patients who had perceived stigma were five times more likely to have a common mental disorder. The current finding is supported by the study findings from Debre Markos City, Ethiopia, ${ }^{41}$ and other studies. ${ }^{24,34,42-45}$ The possible reason is that individuals with internal stigma have a greater likelihood of a stressful and isolated life, since stigma is the main source of loneliness and rage. This may also indicate that stigmatized HIV patients have a higher burden of illness. For that reason, they engage in the abuse of alcohol and other addictive substances. ${ }^{46}$

Likewise, having ten and more years of illness duration among people with HIV/AIDS was a significant factor. It was found that there is a 2.3 times higher risk of the common mental disorder among HIV patients having an illness duration of more than ten years. The possible justification might be prolonged illness, which affects the quality of life, and makes the individual prone to long term involvement in substance abuse, which results in a higher risk of developing psychological and mental problems. ${ }^{47}$ The current finding has not been observed in studies conducted in different parts of the world. Even though the current study has valuable strengths, we admit certain limitations. One of the main limitations was the measurement of resilience level which is too much subjective. The other considerable limitations of this study were it fails to include adherence to the ART regimen as an independent variable.

\section{Conclusion}

In summary, the level of resilience and perceived stigma was found to be an important predictor of common mental disorders among people living with HIV/AIDs. Similarly, being female, single, widowed, or divorced, as well as having a longer illness duration, are all significantly associated with common mental disorders. Hence, improving resilience levels and working to overcome HIV-associated perceived stigma could be a valuable intervention modality. An interventional study is recommended to assess the independent effect of resilience in the improvement of mental and psychological outcomes among chronically ill patients.

\section{Abbreviations}

AOR, Adjusted odds ratio; CI, Confidence interval; SRQ, Self-reporting Questionnaire.

\section{Data Sharing Statement}

All data generated or analyzed during this study are included in this published article. The data set of the current study are available from Solomon Yimer, email: sopsycha@gmail.com; mobile: +251953817580, Dilla university, Dilla, upon reasonable request.

\section{Ethics Approval and Consent to participate}

Ethical approval was obtained from the Institutional Review Board (IRB) of the College of Medicine and Health Sciences (No Committee reference number). Written informed consent was taken from the participants for their voluntary participation. Confidentiality was maintained throughout the study process. The study was conducted in accordance with the Declaration of Helsinki.

\section{Acknowledgments}

We would like to thank the Research and Dissemination Office of Dilla University for funding the research. Our sincere gratitude also goes to the entire staff of the Gedeo Zone health bureau; Yirgacheffe, Bule and Gedeb district hospitals; and the Dilla University referral Hospital ART center staff for their cooperation in making this research a success.

\section{Author Contributions}

Solomon Yimer organized the original investigation; coordinated the collection of data; performed the analysis; wrote the report, and drafted and revised the manuscript. Nebiyu Mengistu, and Zeleke Girma equally contributed 
to the design of the study, and contributed to the statistical analysis and drafting of the manuscript. Seid Shumye contributed to the statistical work and revision of the manuscript. All the authors made significant contributions to the work reported. All authors agreed on the journal to which the article was submitted. Furthermore, all of the authors reviewed and agreed on all versions of the article before submission, and during revision. All authors agreed on the final version accepted for publication, with any significant changes introduced at the proofing stage, and take responsibility for the contents of the article.

\section{Authors' Information}

Solomon Yimer: MSc. in Integrated Clinical and Community Mental Health. Zeleke Girma: MPH. in Public health. Nebiyu Mengistu: MSc. in Integrated Clinical and Community Mental Health. Seid Shumye: MSc. in Integrated Clinical and Community Mental Health.

\section{Funding}

The source of funding for the current research is Dilla University. The funding organization did not have any role in the design of the study, collection, analysis, interpretation of data and in writing the manuscript.

\section{Disclosure}

The authors declare no financial or nonfinancial conflicts of interest for this work.

\section{References}

1. World Health Organization. Data and statistics; 2017 [cited August 20, 2017]. Available from: http://www.who.int/hiv/data/en/. Accessed September 9, 2021.

2. UNAIDS, W. Fact Sheet: World AIDS Day 2017. Global HIV Statistics; 2017.

3. Cal SF, Sá LRD, Glustak ME, et al. Resilience in chronic diseases: a systematic review. Cogent Psychol. 2015;2(1):1024928. doi:10.1080/ 23311908.2015.1024928

4. Morowatisharifabad MA, Movahed E, Farokhzadian J, et al. Antiretroviral therapy adherence and its determinant factors among people living with HIV/AIDS: a case study in Iran. BMC Res Notes. 2019;12(1):1-5. doi:10.1186/s13104-019-4204-5

5. Heestermans T, Browne JL, Aitken SC, et al. Determinants of adherence to antiretroviral therapy among HIV-positive adults in sub-Saharan Africa: a systematic review. BMJ Glob Health. 2016;1 (4):e000125. doi:10.1136/bmjgh-2016-000125

6. Olagunju A, Adeyemi JD, Erinfolami AR, et al. Factors associated with anxiety disorders among HIV-positive attendees of an HIV clinic in Lagos, Nigeria. Int J STD AIDS. 2012;23(6):389-393. doi:10.1258/ ijsa.2011.011200

7. Farinpour R, Miller EN, Satz P, et al. Psychosocial risk factors of HIV morbidity and mortality: findings from the Multicenter AIDS Cohort Study (MACS). J Clin Exp Neuropsychol. 2003;25(5):654-670. doi:10.1076/jcen.25.5.654.14577
8. Do NT, Phiri K, Bussmann H, et al. Psychosocial factors affecting medication adherence among HIV-1 infected adults receiving combination antiretroviral therapy (cART) in Botswana. AIDS Res Hum Retroviruses. 2010;26(6):685-691. doi:10.1089/aid.2009.0222

9. Simoni JM, Frick PA, Huang B. A longitudinal evaluation of a social support model of medication adherence among HIV-positive men and women on antiretroviral therapy. Health Psychol. 2006;25(1):74. doi:10.1037/0278-6133.25.1.74

10. Kessler RC, Üstün TB. The world mental health (WMH) survey initiative version of the world health organization (WHO) composite international diagnostic interview (CIDI). Int $J$ Methods Psychiatr Res. 2004;13(2):93-121. doi:10.1002/mpr.168

11. Brandt N, Rasskazov SV, Popov VK, et al. Potassic specifics of basalts from the Sinii Utes depression: geochemical correlations and problems of K-Ar dating (Southern Primorye region). Russ J Pac Geol. 2009;3(4):374-387. doi:10.1134/S1819714009040058

12. Brandt R. The mental health of people living with HIV/AIDS in Africa: a systematic review. Afr J AIDS Res. 2009;8(2):123-133. doi:10.2989/AJAR.2009.8.2.1.853

13. Graber R, Pichon F, Carabine E. Psychological Resilience: State of Knowledge and Future Research Agendas. London: Overseas Development Institute; 2015.

14. Baldwin G, Kulbok A, Leak C. The wizarding world of resilience. 2017.

15. Sisto A, Vicinanza F, Campanozzi LL, et al. Towards a transversal definition of psychological resilience: a literature review. Medicina. 2019;55(11):745. doi:10.3390/medicina55110745

16. Siriwardhana C, Ali SS, Roberts B, et al. A systematic review of resilience and mental health outcomes of conflict-driven adult forced migrants. Confl Health. 2014;8(1):13. doi:10.1186/1752-1505-8-13

17. De Santis JP, Florom-Smith A, Vermeesch A, et al. Motivation, management, and mastery: a theory of resilience in the context of HIV infection. J Am Psychiatr Nurses Assoc. 2013;19(1):36-46. doi:10.1177/1078390312474096

18. Garrido-Hernansaiz H, Murphy PJ, Alonso-Tapia J. Predictors of resilience and posttraumatic growth among people living with HIV: a longitudinal study. AIDS Behav. 2017;21(11):3260-3270. doi:10.1007/s10461-017-1870-y

19. Dale SK, Cohen MH, Kelso GA, et al. Resilience among women with HIV: impact of silencing the self and socioeconomic factors. Sex Roles. 2014;70(5-6):221-231. doi:10.1007/s11199-014-0348-x

20. Lyons A, Heywood W. Collective resilience as a protective factor for the mental health and well-being of HIV-positive gay men. Psychol Sex Orientat Gend Divers. 2016;3(4):473. doi:10.1037/sgd0000197

21. McGowan JA, Brown J, Lampe FC, et al. Resilience and physical and mental well-being in adults with and without HIV. AIDS Behav. 2018;22(5):1688-1698. doi:10.1007/s10461-017-1980-6

22. Spies G, Seedat S. Depression and resilience in women with HIV and early life stress: does trauma play a mediating role? A cross-sectional study. BMJ Open. 2014;4(2):e004200. doi:10.1136/bmjopen-2013-004200

23. Hobkirk AL, Towe SL, Lion R, et al. Primary and secondary HIV prevention among persons with severe mental illness: recent findings. Curr HIV/ AIDS Rep. 2015;12(4):406-412. doi:10.1007/s11904-015-0294-4

24. Youngmann R, Zilber N, Workneh F, et al. Adapting the SRQ for Ethiopian populations: a culturally-sensitive psychiatric screening instrument. Transcult Psychiatry. 2008;45(4):566-589. doi:10.1177/ 1363461508100783

25. Dale S, Cohen M, Weber K, et al. Abuse and resilience in relation to HAART medication adherence and HIV viral load among women with HIV in the United States. AIDS Patient Care STDS. 2014;28 (3):136-143. doi:10.1089/apc.2013.0329

26. Van Rie A, Sengupta S, Pungrassami P, et al. Measuring stigma associated with tuberculosis and HIV/AIDS in southern Thailand: exploratory and confirmatory factor analyses of two new scales. Trop Med Int Health. 2008;13(1):21-30. doi:10.1111/j.13653156.2007.01971.x 
27. Dalgard O; EUPHIX, EUphact. Social Support-Consequences for Individual and Society. Vol. 16. Bilthoven: RIVM; 2009. Available from: EUphact $\backslash$ Determinantsofhealth $\backslash$ Environment $\backslash$ Socialsupport “ icporder="ext-link-type;;xlink:href" http://www.euphix.org>EUphact $\backslash$ Determinantsofhealth $\backslash$ Environment $\backslash$ Socialsupport. Accessed September 9, 2021.

28. Rutten BP, Hammels C, Geschwind N, et al. Resilience in mental health: linking psychological and neurobiological perspectives. Acta Psychiatr Scand. 2013;128(1):3-20. doi:10.1111/acps.12095

29. Betancourt TS, Meyers-Ohki SE, Charrow A, et al. Annual research review: mental health and resilience in HIV/AIDS-affected children a review of the literature and recommendations for future research. J Child Psychol Psychiatry. 2013;54(4):423-444. doi:10.1111/j.14697610.2012.02613.x

30. Li X, Chi P, Sherr L, et al. Psychological resilience among children affected by parental HIV/AIDS: a conceptual framework. Health Psychol Behav Med. 2015;3(1):217-235. doi:10.1080/ 21642850.2015.1068698

31. Dufour CA, Marquine MJ, Fazeli PL, et al. A longitudinal analysis of the impact of physical activity on neurocognitive functioning among HIV-infected adults. AIDS Behav. 2018;22(5):1562-1572. doi:10.1007/s10461-016-1643-z

32. Zlatar ZZ, Towler S, McGregor KM, et al. Functional language networks in sedentary and physically active older adults. J Int Neuropsychol Soc. 2013;19(6):625-634. doi:10.1017/S1355617713000246

33. Wirth MD, Jaggers JR, Dudgeon WD, et al. Association of markers of inflammation with sleep and physical activity among people living with HIV or AIDS. AIDS Behav. 2015;19(6):1098-1107. doi:10.1007/ s10461-014-0949-y

34. Duko B, Toma A, Abraham Y. Prevalence and correlates of common mental disorder among HIV patients attending antiretroviral therapy clinics in Hawassa City, Ethiopia. Ann Gen Psychiatry. 2019;18 (1):17. doi:10.1186/s12991-019-0241-7

35. Bahrami F, Yousefi N. Females are more anxious than males: a metacognitive perspective. Iran J Psychiatry Behav Sci. 2011;5(2):83.

36. Ball J. Women $40 \%$ more likely than men to develop mental illness, study finds. The Guardian. 2013;22.

37. Chibanda D, Cowan F, Gibson L, et al. Prevalence and correlates of probable common mental disorders in a population with high prevalence of HIV in Zimbabwe. BMC Psychiatry. 2016;16(1):55. doi:10.1186/s12888-016-0764-2
38. Basha EA, Derseh BT, Haile YGE, et al. factors affecting psychological distress among people living with HIV/AIDS at selected hospitals of north Shewa zone, Amhara region, Ethiopia. AIDS Res Treat. 2019;2019:1-8. doi:10.1155/2019/8329483

39. Trivedi J, Sareen H, Dhyani M. Psychological aspects of widowhood and divorce. Mens Sana Monogr. 2009;7(1):37. doi:10.4103/09731229.40648

40. Myer L, Smit J, Roux LL, et al. Common mental disorders among HIV-infected individuals in South Africa: prevalence, predictors, and validation of brief psychiatric rating scales. AIDS Patient Care STDS. 2008;22(2):147-158. doi:10.1089/apc.2007.0102

41. Zewdu S, Abebe N. Common mental disorder among HIV infected individuals at comprehensive HIV care and treatment clinic of Debre Markos referral Hospital, Ethiopia. J AIDS Clin Res. 2015;6(2):420. doi:10.4172/2155-6113.1000420

42. Tesfaye SH, Bune GT. Generalized psychological distress among HIV-infected patients enrolled in antiretroviral treatment in Dilla University Hospital, Gedeo zone, Ethiopia. Glob Health Action. 2014;7(1):23882. doi:10.3402/gha.v7.23882

43. Yi S, Chhoun P, Suong S, et al. AIDS-related stigma and mental disorders among people living with HIV: a cross-sectional study in Cambodia. PLoS One. 2015;10(3):e0121461. doi:10.1371/journal. pone. 0121461

44. HIV/AIDS, J.U.N.P.o. People Living with HIV Stigma Index: Asia Pacific Regional Analysis. Geneva, Switzerland: UNAIDS; 2011.

45. Abebe H, Shumet S, Nassir Z, et al. Prevalence of depressive symptoms and associated factors among HIV-positive youth attending ART follow-up in Addis Ababa, Ethiopia. AIDS Res Treat. 2019;2019:1-7. doi:10.1155/2019/4610458

46. Levi-Minzi MA, Surratt HL. HIV stigma among substance abusing people living with HIV/AIDS: implications for HIV treatment. AIDS Patient Care STDS. 2014;28(8):442-451. doi:10.1089/ apc. 2014.0076

47. Association, C.M.H. The Relationship Between Mental Health, Mental Illness and Chronic Physical Conditions. Ottawa: Canadian Mental Health Association; 2008.
HIV/AIDS - Research and Palliative Care

\section{Publish your work in this journal}

HIV/AIDS - Research and Palliative Care is an international, peerreviewed open-access journal focusing on advances in research in HIV, its clinical progression and management options including antiviral treatment, palliative care and public healthcare policies to
Dovepress

control viral spread. The manuscript management system is completely online and includes a very quick and fair peer-review system, which is all easy to use. Visit http://www.dovepress.com/testimonials.php to read real quotes from published authors. 